Article

\title{
Studying the Ring-Opening Polymerization of 1,5-Dioxepan-2-one with Organocatalysts
}

\author{
Jinbao Xu *, Yang Chen, Wenhao Xiao, Jie Zhang, Minglu Bu, Xiaoqing Zhang and Caihong Lei * \\ Guangdong Provincial Key Laboratory of Functional Soft Condensed Matter, School of Materials and Energy, \\ Guangdong University of Technology, Guangzhou 510006, China; 15914486750@163.com (Y.C.); \\ xujunbao001@163.com (W.X.); zhangjiez2019@163.com (J.Z.); buminglu@outlook.com (M.B.); \\ zhangxq@gdut.edu.cn (X.Z.) \\ * Correspondence: xujinbao@gdut.edu.cn (J.X.); lch528@gdut.edu.cn (C.L.)
}

Received: 23 September 2019; Accepted: 8 October 2019; Published: 10 October 2019

check for updates

\begin{abstract}
Three different organocatalysts, namely, 1-tert-butyl-4,4,4-tris(dimethylamino)-2,2-bis[tris (dimethylamino) phosphoranylidenamino]-2 $\Lambda^{5}, 4 \Lambda^{5}$-catenadi(phosphazene) $\quad\left(t\right.$ - $\left.\mathrm{BuP}_{4}\right), \quad 1,5,7-$ triazabicyclo[4.4.0]dec-5-ene (TBD) and 1,8-diazabicyclo[5.4.0]undec-7-ene (DBU), have been used as 1,5-dioxepan-2-one (DXO) ring-opening polymerization (ROP) catalysts at varied reaction conditions. ${ }^{1} \mathrm{H}$ NMR spectra, size exclusion chromatography (SEC) characterizations, and kinetic studies prove that the (co)polymerizations are proceeded in a controlled manner with the three organocatalysts. It is deduced that $t-\mathrm{BuP}_{4}$ and DBU catalysts are in an initiator/chain end activated ROP mechanism and TBD is in a nucleophilic ROP mechanism.
\end{abstract}

Keywords: 1,5-dioxepan-2-one; $t$-BuP 4 ; DBU; TBD; organocatalyst

\section{Introduction}

During the last several decades, for the ring-opening polymerization (ROP) of cyclic esters, transition metal and organometallic compounds were commonly used as initiators or polymerization catalysts [1-4]. Notwithstanding the polymerization processes are very successful in producing degradable polyesters and polycarbonates, it is clear that the metallic-based compounds are environmentally sensitive, and a lack of residual metal contaminants is required in biomedical and microelectronic applications [5-7]. For the last two decades, organocatalysts have provided a powerful strategy for the ROP of cyclic monomers, e.g., lactones, epoxides or carbonates, as the advantages of convergence of convenience, fast rates, functional group tolerance, selectivity and easy separating. Polyesters, polycarbonates, poly(ethylene oxide)s, polyphosphoesters and polysiloxanes, etc., have been well defined with a controlled manner in molecular weight, molecular weight distribution, end groups, architecture, stereoregularity and monomers sequence by an organic acid or base catalysts [8-16]. Among the various organocatalysts, the most studied were phosphazenes, guanidines, and amidines. Hedrick and coworkers have prepared polycarbonates, polylactides with excellent controlling and functionality using 1,5,7-triazabicyclo[4.4.0]dec-5-ene (TBD) and 1,8-diazabicyclo[5.4.0]undec-7-ene (DBU) as the organocatalysts [17-22]. Zhao and Zhang's group have developed a number of poly(ethylene oxide) based copolymers and polymerization methods with phosphazene catalysts [23-26]. Although organocatalysts have been widely studied for ROP, they have not been used as catalyst for ROP of cyclic 1,5-dioxepan-2-one (DXO) as far as we know.

DXO homopolymer is hydrophilic and completely amorphous with a low glass transition temperature $\left(T_{\mathrm{g}}\right)$ of approximately $-39^{\circ} \mathrm{C}$ [27]. DXO based (co)polymers undergo hydrolysis in vitro and vivo, and is, therefore, a possible candidate in the design of bio-absorbable materials [28-30]. In the same time, these properties are very useful in a degradable copolymer with the hydrophobic 
and semi-crystalline segments, such as poly( $\varepsilon$-caprolactone) (PCL) and poly(lactide) (PLA). Copolymerization of DXO and other cyclic esters has been investigated to modify and improve the degradation properties. Statistical copolymers of DXO with lactide have shown interesting properties on degradation rates and stiffness, which could be easily altered [31].

In the present work, we have studied the ROP of DXO with three different organacatalysts, 1-tert-butyl-4,4,4-tris(dimethylamino)-2,2-bis[tris(dimethylamino)phosphoranylidenamino]- $2 \Lambda^{5}, 4 \Lambda^{5}$ catenadi(phosphazene) $\left(t-\mathrm{BuP}_{4}, \mathrm{MeCN}_{\mathrm{pKa}}\right.$ is 42.6), 1,5,7-triazabicyclo[4.4.0]dec-5-ene (TBD, ${ }^{\mathrm{MeCN}_{\mathrm{pKa}}}$ is 26) and 1,8-diazabicyclo[5.4.0] undec-7-ene (DBU, ${ }^{\mathrm{MeCN}} \mathrm{pKa}$ is 24.3$)$, which have verified basicity, catalytic reactivity and chemical structure (Scheme 1) [8]. We have also explored the copolymerization of DXO with CL and the initiation with poly(ethylene glycol) monomethyl ether ( $m$ PEG) as macroinitiator, our aim is to well know the ROP process of DXO with organocatalysts which may be useful in synthesizing biodegradable materials.

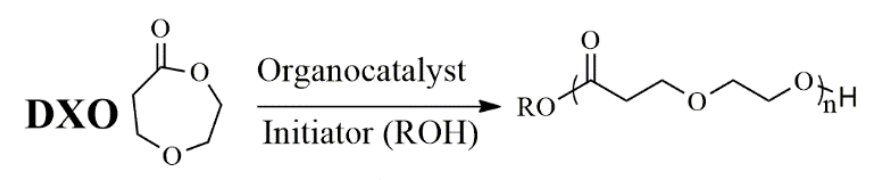<smiles>CN(C)P(=N[P+](N=P(N(C)C)(N(C)C)N(C)C)(N=P(N(C)C)(N(C)C)N(C)C)N=P(N(C)C)(N(C)C)N(C)C)(N(C)C)N(C)C</smiles>

Scheme 1. Ring-opening polymerization of 1,5-dioxepan-2-one (DXO) with $t$-BuP $4,1,8$-diazabicyclo [5.4.0] undec-7-ene (DBU) and 1,5,7-triazabicyclo[4.4.0]dec-5-ene (TBD) as organocatalysts.

\section{Materials and Methods}

\subsection{Materials}

DXO was synthesized through Bayer-Villiger oxidation according to the literature, then purified by recrystallization from the dry ether, and two subsequent distillations under reduced pressure [32,33]. $\varepsilon$-Caprolactone (CL) from Aldrich (Shanghai, China) was dried over calcium hydride $\left(\mathrm{CaH}_{2}\right)$ and distilled under reduced pressure prior to use. Ethylene glycol (EG) and benzyl alcohol ( $\mathrm{BnOH})$ from Sinopharm (Shanghai, China) were dried over sodium with protective nitrogen atmosphere and distilled under reduced pressure prior to use. Tetrahydrofuran (THF) and toluene (TOL) from Sinopharm (Shanghai, China) were freshly distilled from sodium/benzophenone and stored under an argon atmosphere. DBU, TBD, $t$-BuP 4 from Aldrich (Shanghai, China) were used as received, and other reagents from Sinopharm (Shanghai, China) were also used as received.

\subsection{Characterizations}

Proton nuclear magnetic resonance $\left({ }^{1} \mathrm{H}\right.$ NMR) spectra were recorded on a Bruker AV400 NMR spectrometer (Rheinstetten, Germany) by using deuterated chloroform $\left(\mathrm{CDCl}_{3}\right)$ or benzene $\left(\mathrm{C}_{6} \mathrm{D}_{6}\right)$ as the solvent and tetramethylsilane (TMS) as the internal standard. The apparent number average molecular weight $\left(M_{n}\right)$ and polydispersity index (PDI) were measured at $35{ }^{\circ} \mathrm{C}$ on a Waters size exclusion chromatography (SEC) (Milford, USA) equipped with a model 510 pump, two identical PL gel columns (5 $\mu \mathrm{m}$, MIXED-C) and a differential refractive index detector model 410 (RI). A series of monodisperse polystyrenes were used as the standards with THF as the eluent at a flow rate of $1.0 \mathrm{~mL} / \mathrm{min}$. 


\subsection{Synthesis of PDXO Homopolymer}

A typical polymerization was performed as follows: DXO $(0.58 \mathrm{~g}, 5.0 \mathrm{mmol}, 100$ equiv $)$ and $\mathrm{BnOH}(5.0 \mu \mathrm{L}, 0.05 \mathrm{mmol}, 1.0$ equiv) were added to a flask with purified THF $(2 \mathrm{~mL})$ at room temperature. $t$ - $\mathrm{BuP}_{4}(50 \mu \mathrm{L}, 0.05 \mathrm{mmol}, 1.0$ equiv in hexane) was then added with a syringe to initiate the polymerization (most of the polymerization was handled in the glove box). For kinetic study, aliquots were withdrawn in an argon flow with designed time in order to monitor monomer conversions and evolution of molar masses. The polymerization was quenched by adding $0.1 \mathrm{~mL}$ acetic acid, a small amount of the polymerization mixture was withdrawn and dissolved with $\mathrm{CDCl}_{3}$ for ${ }^{1} \mathrm{H} \mathrm{NMR}$ analysis and further diluted with THF for SEC measurement to obtain $M_{n}$ and PDI. The rest polymerization mixture was diluted with THF and poured into a large excess of cold ether to precipitate the polymer which was then dried under vacuum. Polymerization of DXO with TBD, DBU and $t-\mathrm{BuP}_{4}$ as the catalyst under other conditions was carried out in a similar procedure (Table 1). ${ }^{1} \mathrm{H}$ NMR $(400 \mathrm{MHz}$, $\left.\mathrm{CDCl}_{3}, \delta, \mathrm{ppm}\right): 4.22\left(-\mathrm{COCH}_{2} \mathrm{CH}_{2} \mathrm{OCH}_{2} \mathrm{CH}_{2} \mathrm{O}-, 2 \mathrm{H}\right), 3.75\left(-\mathrm{COCH}_{2} \mathrm{CH}_{2} \mathrm{OCH}_{2} \mathrm{CH}_{2} \mathrm{O}-, 2 \mathrm{H}\right)$, $3.65\left(-\mathrm{COCH}_{2} \mathrm{CH}_{2} \mathrm{OCH}_{2} \mathrm{CH}_{2} \mathrm{O}-, 2 \mathrm{H}\right), 2.61\left(-\mathrm{COCH}_{2} \mathrm{CH}_{2} \mathrm{OCH}_{2} \mathrm{CH}_{2} \mathrm{O}-, 2 \mathrm{H}\right)$.

Table 1. Characterization data of ring-opening polymerization (ROP) of DXO with three organocatalysts at various conditions ${ }^{\mathrm{a}}$.

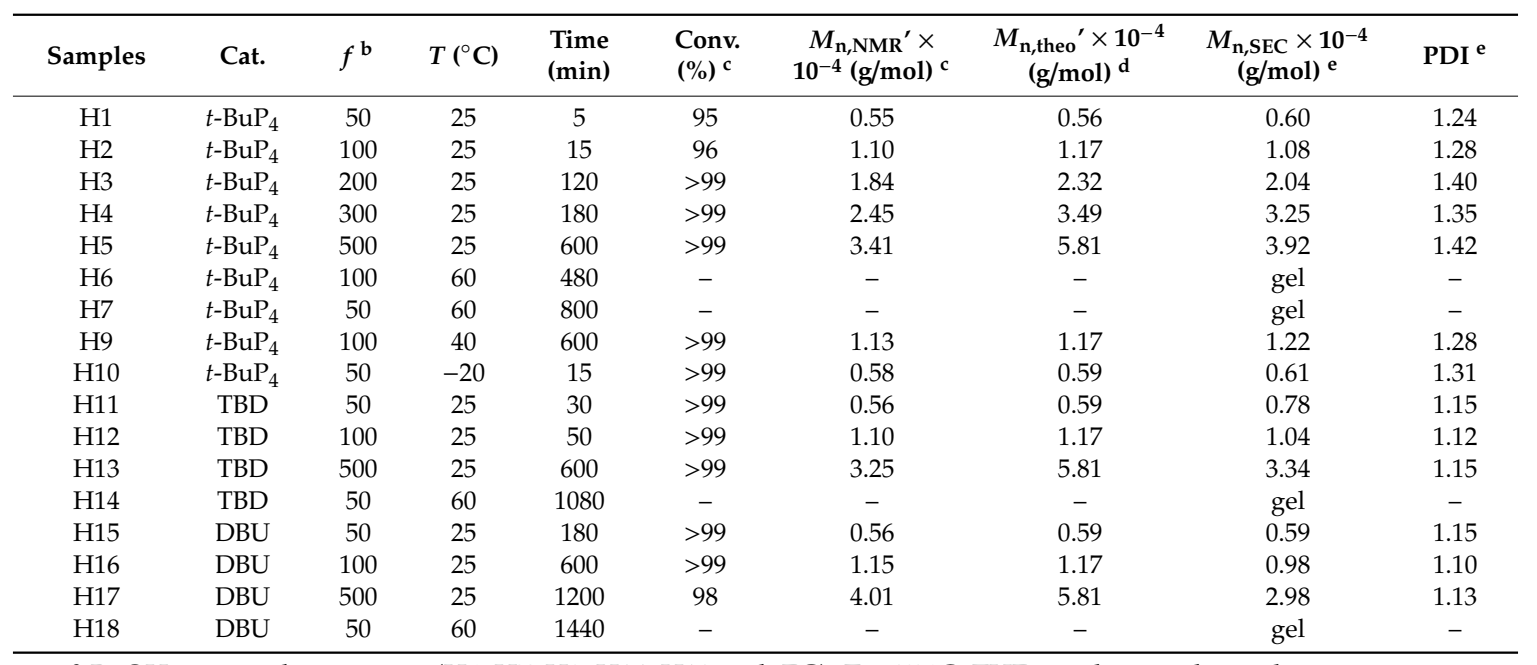

${ }^{\text {a }} \mathrm{BnOH}$ was used as initiator (H6, H7, H9, H14, $\mathrm{H} 18$ with EG), $\mathrm{T}=25^{\circ} \mathrm{C}$, THF as solvent, other polymerization at $60{ }^{\circ} \mathrm{C}$ was in bulk; ${ }^{\mathrm{b}}$ molar ratio of DXO to initiator; ${ }^{\mathrm{c}}$ calculated from ${ }^{1} \mathrm{H}$ NMR analysis; ${ }^{\mathrm{d}}$ calculated from $\left([\mathrm{M}]_{0} /[\mathrm{I}]_{0}\right)$ $\times$ monomer conversion $\times\left(M_{\mathrm{W}}\right.$ of DXO $)+\left(M_{\mathrm{W}}\right.$ of initiator); ${ }^{\mathrm{e}}$ Obtained from SEC (size exclusion chromatography) analysis. PDI, polydispersity index.

\subsection{Synthesis of Copolymer}

A typical procedure for copolymerization was performed as follows: DXO $(0.58 \mathrm{~g}, 5.0 \mathrm{mmol}$, 50 equiv), $\mathrm{CL}(0.57 \mathrm{~g}, 5.0 \mathrm{mmol}, 50$ equiv) and $\mathrm{BnOH}(5.0 \mu \mathrm{L}, 0.05 \mathrm{mmol}, 1.0$ equiv) were added to a flask with THF at room temperature in glove box. $t$-BuP $4(50 \mu \mathrm{L}, 0.05 \mathrm{mmol}, 1.0$ equiv in hexane) was then added with a syringe to initiate the polymerization. The polymerization was quenched by adding $0.1 \mathrm{~mL}$ acetic acid and diluted with THF, which was then poured into a large excess of cold ether to precipitate the copolymer. The obtained copolymer was then dried under vacuum for further analysis. Copolymerization of $m \mathrm{PEG}$ and $\mathrm{DXO}$ was proceeded in a similar manner. ${ }^{1} \mathrm{H} \mathrm{NMR}$ (400 MHz, $\left.\mathrm{CDCl}_{3}, \delta, \mathrm{ppm}\right): 4.22\left(-\mathrm{COCH}_{2} \mathrm{CH}_{2} \mathrm{OCH}_{2} \mathrm{CH}_{2} \mathrm{O}-, 2 \mathrm{H}\right), 4.06\left(-\mathrm{COCH}_{2}\left(\mathrm{CH}_{2}\right)_{3} \mathrm{CH}_{2} \mathrm{O}-\right.$, $2 \mathrm{H}), \quad 3.75\left(-\mathrm{COCH}_{2} \mathrm{CH}_{2} \mathrm{OCH}_{2} \mathrm{CH}_{2} \mathrm{O}-, \quad 2 \mathrm{H}\right), \quad 3.65\left(-\mathrm{COCH}_{2} \mathrm{CH}_{2} \mathrm{OCH}_{2} \mathrm{CH}_{2} \mathrm{O}-, \quad 2 \mathrm{H}\right), \quad 2.61$ $\left(-\mathrm{COCH}_{2} \mathrm{CH}_{2} \mathrm{OCH}_{2} \mathrm{CH}_{2} \mathrm{O}-, 2 \mathrm{H}\right), 2.25\left(-\mathrm{COCH}_{2}\left(\mathrm{CH}_{2}\right)_{3} \mathrm{CH}_{2} \mathrm{O}-, 2 \mathrm{H}\right), 1.66\left(-\mathrm{COCH}_{2} \mathrm{CH}_{2} \mathrm{CH}_{2} \mathrm{CH}_{2} \mathrm{CH}_{2} \mathrm{O}-\right.$, $4 \mathrm{H}), 1.33\left(-\mathrm{COCH}_{2} \mathrm{CH}_{2} \mathrm{CH}_{2} \mathrm{CH}_{2} \mathrm{CH}_{2} \mathrm{O}-, 2 \mathrm{H}\right)$. 


\section{Results and Discussion}

\subsection{Polymerization}

Polymerization of DXO was first proceeded with benzyl alcohol as the initiator because the incorporation of benzyl-ester end group could be easily detected by ${ }^{1} \mathrm{H}$ NMR measurement. Table 1 presents the results of DBU, TBD and $t-\mathrm{BuP}_{4}$ catalyzed ROP of DXO at varied reaction conditions. The $M_{\mathrm{n}}$ of PDXO increases with the increasing of monomer/initiator ratio indicates that the polymerization is in a controlled manner, and we can prepare the polymers with the molecular weight as designed. The PDI for all the prepared polymers are narrow, and it becomes a little wider with the catalyst basicity increasing. Reaction time for reaching the designed $M_{n}$ of these organocatalysts is much lower compared with other DXO ROP catalysts, and it decreases with the organocatalysts basicity increasing [34,35]. The conversion can reach 99\% even proceeding the polymerization at $-20{ }^{\circ} \mathrm{C}$ indicates that the reactivity of $t-\mathrm{BuP}_{4}$ catalyzed $\mathrm{DXO}$ polymerization is so high. When we raise the temperature to $60^{\circ} \mathrm{C}$, there is some interesting phenomenon for all the three catalysts. We just obtained gel after the designed reaction time, and this will be discussed below.

Figure 1 shows the ${ }^{1} \mathrm{H}$ NMR spectra of $\mathrm{DXO}$ and $\mathrm{PDXO}$ with $t$ - $\mathrm{BuP}_{4}$ as the catalyst. The signals, due to the protons of DXO, PDXO main chain along with minor signals at 7.34,5.20 ppm, due to the phenyl protons of $\mathrm{BnO}-$ and the methylene protons adjacent to the ester linkage for $\mathrm{BnOH}$ moiety of the initiator are observed. In addition, the peak, due to the methylene protons being adjacent to the $\omega$-chain end of the hydroxyl group, is clearly observed at $3.70 \mathrm{ppm}$, and the peak area is comparable to that of the methylene protons of $\mathrm{BnOH}$, indicating good chain-end fidelity. Moreover, the number average molecular weight of the polymer estimated from ${ }^{1} \mathrm{H}$ NMR fairly agrees with that calculated from the monomer/initiator ratio and the monomer conversion (Table 1). These results indicate that polymers have the expected structure with a $\omega$-chain-end hydroxyl group and $\alpha$-chain-end benzyl group, providing one way to synthesize telechelic PDXO and PDXO-based block copolymers. Similar results could also be concluded from TBD and DBU catalyzed ROP of DXO.

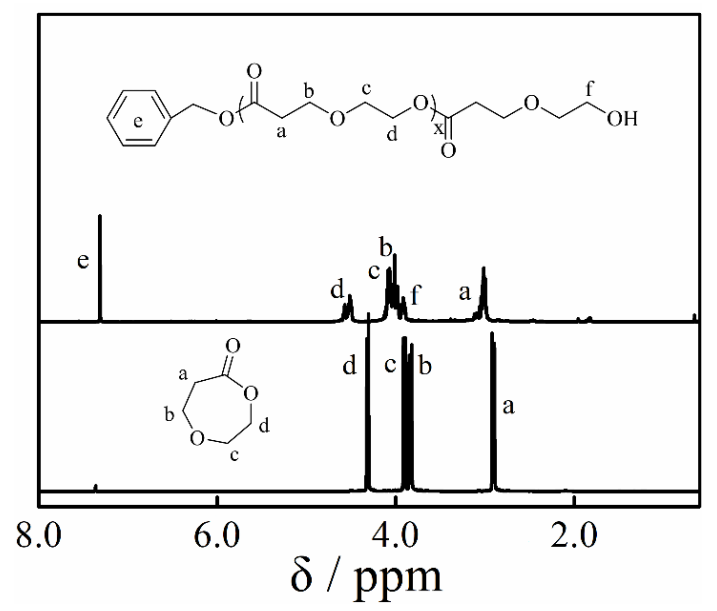

Figure 1. ${ }^{1} \mathrm{H}$ NMR spectra for DXO and PDXO (Table 1, H1).

\subsection{Ether Bond Fragmentation}

Figure 2 shows ${ }^{1} \mathrm{H}$ NMR spectrum of PDXO synthesized in bulk at $60{ }^{\circ} \mathrm{C}$ with $t$-BuP 4 as the catalyst (Table 1, H6). The aliquot sample was taken out of reaction flask after $2 \mathrm{~h}$ and quenched for ${ }^{1} \mathrm{H}$ NMR analysis. In addition to the signals for PDXO main chain, three new signals appear at 5.8, 6.2, $6.5 \mathrm{ppm}$ which could be attributed to the three protons of double bonds, respectively. Albertsson et al. have reported this phenomenon in stannous 2-ethylhexanoate $\left(\mathrm{Sn}(\mathrm{Oct})_{2}\right)$ catalyzed ROP of DXO with a temperature high than $120^{\circ} \mathrm{C}$ and the unsaturated chain-end were deduced from the ether bond fragmentation [36]. However, in our experiments, the ether bond fragmentation proceeded only at 60 
${ }^{\circ} \mathrm{C}$ when using the three organocatalysts, and the resulted double bonds reacted spontaneously to form crosslinks between the polymer chains producing a gel after 6,16 and $24 \mathrm{~h}$, respectively. We speculate that the organocatalysts with high basicity could accelerate the ether bond fragment, and a suggested fragment pathway is shown in Scheme 2. The spontaneous reaction of unsaturated double bonds induced during thermal fragmentation of ether bonds may provide one new way for synthesizing degradable hydrogels.

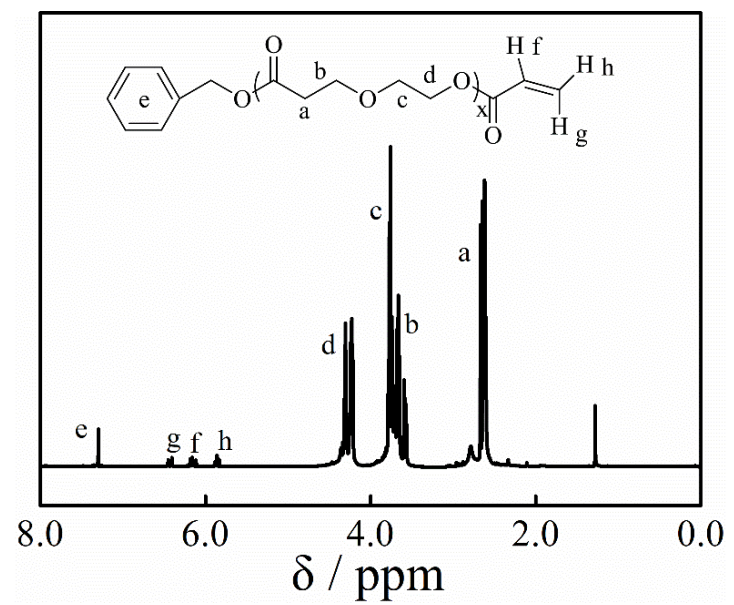

Figure 2. ${ }^{1} \mathrm{H}$ NMR spectrum of PDXO catalyzed with $t$-BuP 4 in bulk at $60{ }^{\circ} \mathrm{C}(2 \mathrm{~h})$ (Table $\left.1, \mathrm{H} 6\right)$.

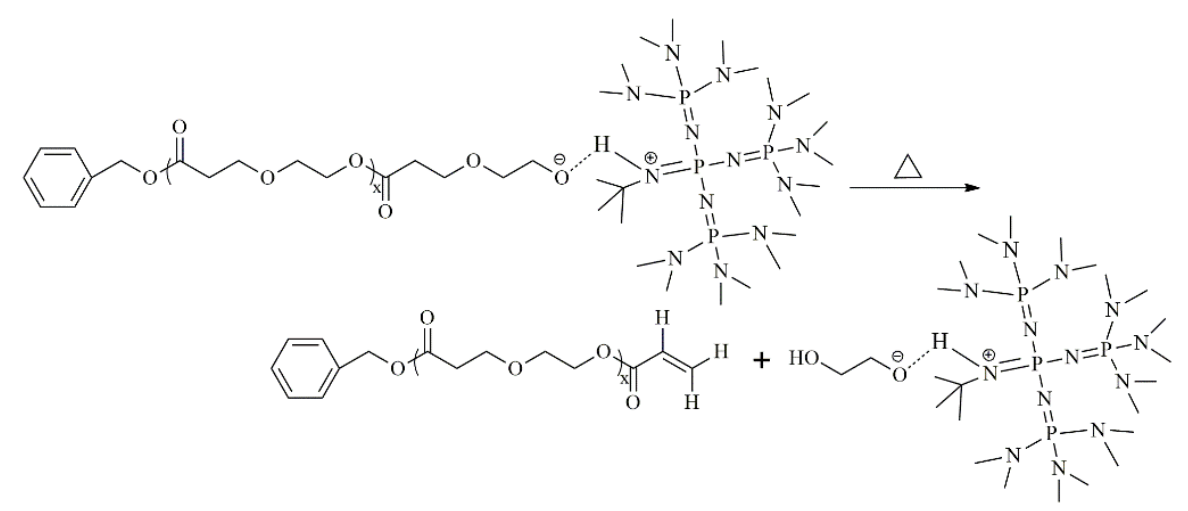

Scheme 2. Suggested ether bond fragmentation pathway during organo-catalytic DXO polymerization.

\subsection{Kinetic Study}

To further confirm the controlled manner of organo-catalyzed ROP of DXO, we analyzed the $M_{\mathrm{n}}$ and PDI of the resulting PDXO as a function of the monomer conversion. The plot of $M_{\mathrm{n}}$ versus conversion is almost linear up to a high monomer conversion suggesting that the depletion of monomer in the reaction system is constant during the polymerization process (Figure 3A). The PDI of PDXO remains constant narrow throughout the polymerization, indicating that the transesterification effect is faint for the three organacatalysts. In addition, $M_{\mathrm{n}}$ increases to higher value with the increase in monomer conversion and the final $M_{n}$ becomes higher with higher monomer to initiator ratio while maintaining narrow PDI with $t$-BuP 4 as the catalyst (Figure 3B). These results clearly indicate that the organo-catalyzed ROP of DXO is in a controlled manner.

Kinetics experiments were carried out to verify the kinetic order throughout the polymerization process. As shown in Figure 4A, the first-order relationship between $\ln \left([\mathrm{DXO}]_{0} /[\mathrm{DXO}]\right)$ and the reaction time with DBU, TBD and $t-\mathrm{BuP}_{4}$ as the ROP catalysts of DXO is observed. When TBD is used as a catalyst, the conversion of DXO reaches a level of more than $75 \%$ within $20 \mathrm{~min}$, and the conversion is just $38 \%$ with DBU as the catalyst. Nevertheless, the conversion of DXO reaches a level of more than 
$99 \%$ within $10 \mathrm{~min}$ when $t-\mathrm{BuP}_{4}$ is used as the catalyst. We speculate that the highest catalytic activity for $t-\mathrm{BuP}_{4}$ is attributed to its super basicity.
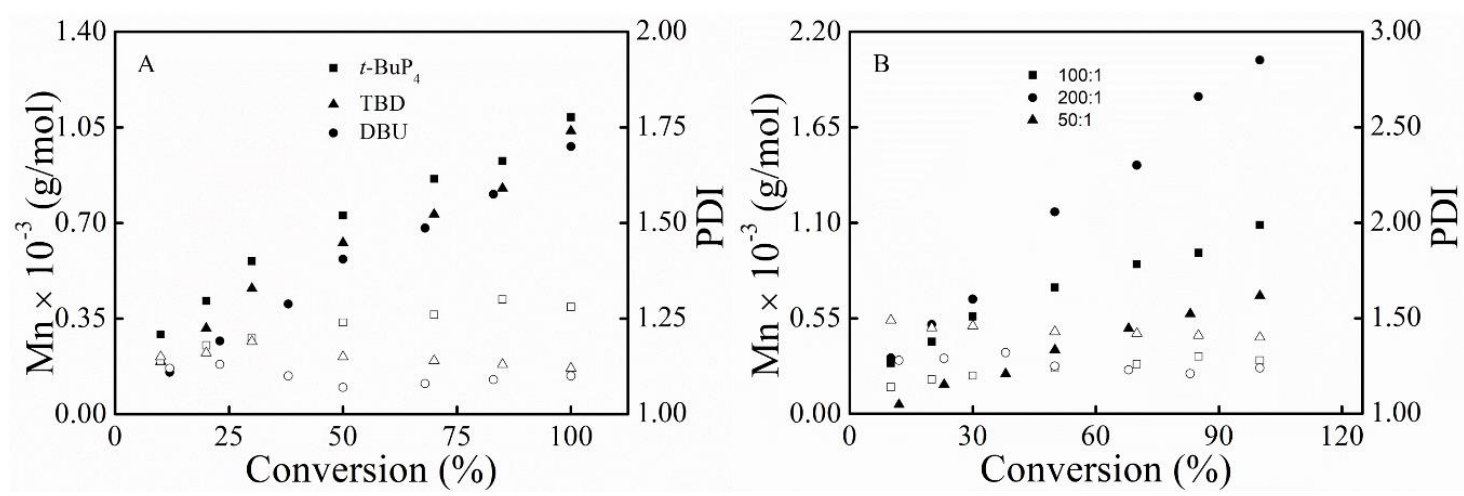

Figure 3. (A) $M_{\mathrm{n}}$ (solid) and PDI (hollow) versus monomer conversion for the ROP of DXO with $t$-BuP 4 (square), TBD (triangle) and DBU (circle) as catalysts ([M $\left.]_{0} /[\mathrm{I}]_{0}=100 / 1\right) ;(B) M_{\mathrm{n}}$ (solid) and PDI (hollow) versus monomer conversion for different monomer to initiator ratio with $t$ - $\mathrm{BuP}_{4}$ as catalyst.
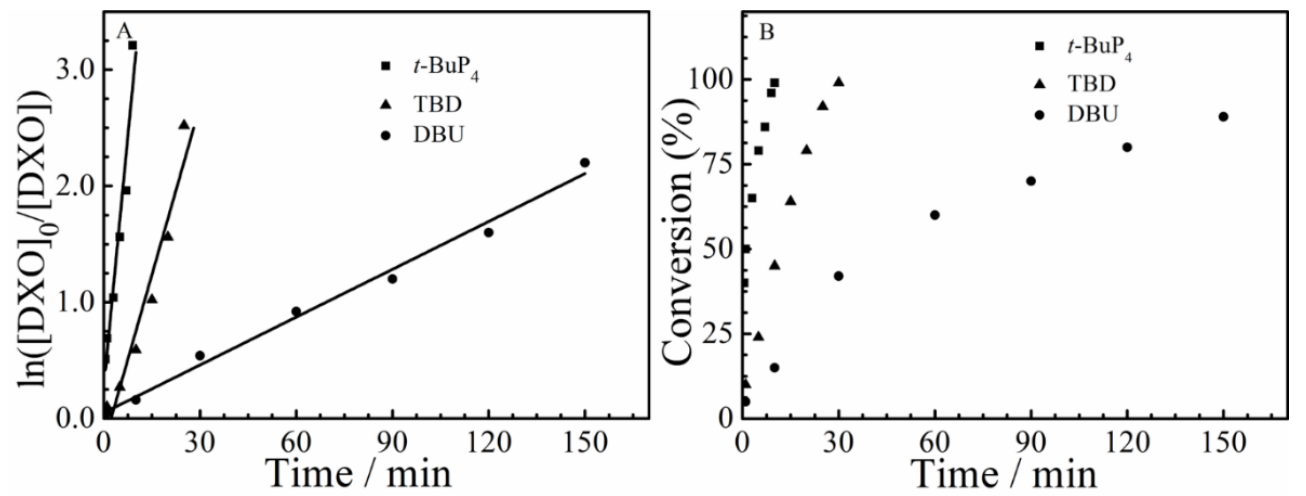

Figure 4. (A) Kinetic plots $\left([\mathrm{DXO}]_{0} /[\mathrm{I}]_{0}=50 / 1\right)$ and $(\mathbf{B})$ dependence of monomer conversion on reaction time for the ROP of DXO with $t$ - $\mathrm{BuP}_{4}$ (square), TBD (triangle) and DBU (circle) as catalysts.

\subsection{Copolymerization and Macroinitiator Initiation}

Copolymerization is the most-used route to modify and improve the properties of polymers, we proceeded the copolymerization of DXO/CL, and $m$ PEG $\left(M_{n}=2000\right)$ was also used as the macroinitiator with the three catalysts. From Table 2 we can see that $m$ PEG with one chain-end hydroxyl could initiate the ROP of DXO successfully; thus, a new kind of amphiphilic copolymers could be obtained. The $M_{n}$ of the copolymers are as designed, the PDI are narrow, and the monomer molar ratio in the final copolymers are consistent with the initial monomers feeding calculated from ${ }^{1} \mathrm{H}$ NMR (Figure 5). These results deeply demonstrate that the organo-catalyzed ROP of DXO is in a controlled manner.

Table 2. Characterization data of DXO based copolymers ${ }^{\mathrm{a}}$.

\begin{tabular}{cccccc}
\hline Samples & Initiators & Catalysts & $f^{\mathbf{b}}$ & $\left.\boldsymbol{M}_{\mathbf{n}} \times \mathbf{1 0}^{\mathbf{4}} \mathbf{( g / m o l}\right)^{\mathbf{c}}$ & PDI $^{\mathbf{c}}$ \\
\hline S1 & $m$ PEG $_{2000}-\mathrm{OH}$ & $t-\mathrm{BuP}_{4}$ & $\mathrm{DXO}$ & 0.72 & 1.24 \\
S2 & $m \mathrm{PEG}_{2000}-\mathrm{OH}$ & $\mathrm{TBD}$ & $\mathrm{DXO}$ & 0.70 & 1.14 \\
$\mathrm{~S} 3$ & $m \mathrm{PEG}_{2000}-\mathrm{OH}$ & $\mathrm{DBU}$ & $\mathrm{DXO}$ & 0.73 & 1.10 \\
$\mathrm{~S} 4{ }^{\mathrm{c}}$ & $\mathrm{BnOH}$ & $t-\mathrm{BuP}_{4}$ & $\mathrm{CL} / \mathrm{DXO}$ & 1.03 & 1.37 \\
$\mathrm{~S} 5$ & $\mathrm{BnOH}$ & $\mathrm{TBD}$ & $\mathrm{CL} / \mathrm{DXO}$ & 1.03 & 1.27 \\
S6 & $\mathrm{BnOH}$ & $\mathrm{DBU}$ & $\mathrm{CL} / \mathrm{DXO}$ & 1.12 & 1.09 \\
\hline
\end{tabular}

a $T=25^{\circ} \mathrm{C}$, THF as solvent; ${ }^{\mathrm{b}}$ Molar ratio of monomer to initiator is 100:1, molar ratio of CL:DXO $=1: 1$; $^{\mathrm{c}}$ Obtained from SEC. 


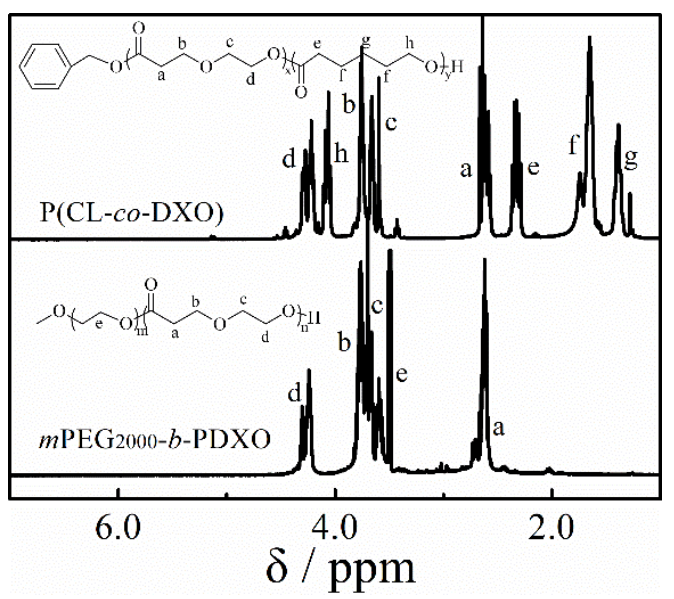

Figure 5. ${ }^{1} \mathrm{H}$ NMR spectra of $\mathrm{P}(\mathrm{CL}-c o-\mathrm{DXO})$ and $m \mathrm{PEG}_{2000}-b$-PDXO copolymers with $t$ - $\mathrm{BuP}_{4}$ as a catalyst.

\subsection{Proposed Mechanism}

We finally focused on the mechanism of these polymerizations, and ${ }^{1} \mathrm{H}$ NMR was used to explore the possible interaction of the components in the polymerization system. Hedrick and coworkers have also used NMR to elucidate the mechanism of ROP with organocatalysts, and they indicated that MTBD form hydrogen bonds to the alcohol of an initiator [20]. Figure 6A shows the ${ }^{1} \mathrm{H}$ NMR spectra of $\mathrm{BnOH}, t-\mathrm{BuP}_{4}$ and their 1:1 complex in $\mathrm{C}_{6} \mathrm{D}_{6}$. For the mixture, the downfield shift of the peaks for the methylene protons of benzyl alcohol is observed from 4.3 to $5.4 \mathrm{ppm}$, while the upfield shift for tert-butyl protons of $t$ - $\mathrm{BuP}_{4}$ is observed from 1.80 to $1.36 \mathrm{ppm}$ and from 2.74 to $2.48 \mathrm{ppm}$ for methyl protons. These results indicate that $\mathrm{BnOH}$ is deprotonated by $t-\mathrm{BuP}_{4}$ to form $\mathrm{BnO}^{-} \cdot\left[t-\mathrm{BuP}_{4}, \mathrm{H}\right]^{+}$as shown in Scheme 3, which act as the initiating activation center in the ROP process of DXO. ROP of $\mathrm{DXO}$ with $t$ - $\mathrm{BuP}_{4}$ catalyst then occurs through an initiator/chain-end polymerization mechanism by activation initiator or chain-end hydroxyls. Figure $6 \mathrm{~B}$ shows the ${ }^{1} \mathrm{H}$ NMR spectra of $\mathrm{BnOH}, \mathrm{DBU}$ and their 1:1 complex in $\mathrm{C}_{6} \mathrm{D}_{6}$ and we conclude the similar results as in $t-\mathrm{BuP}_{4}$.
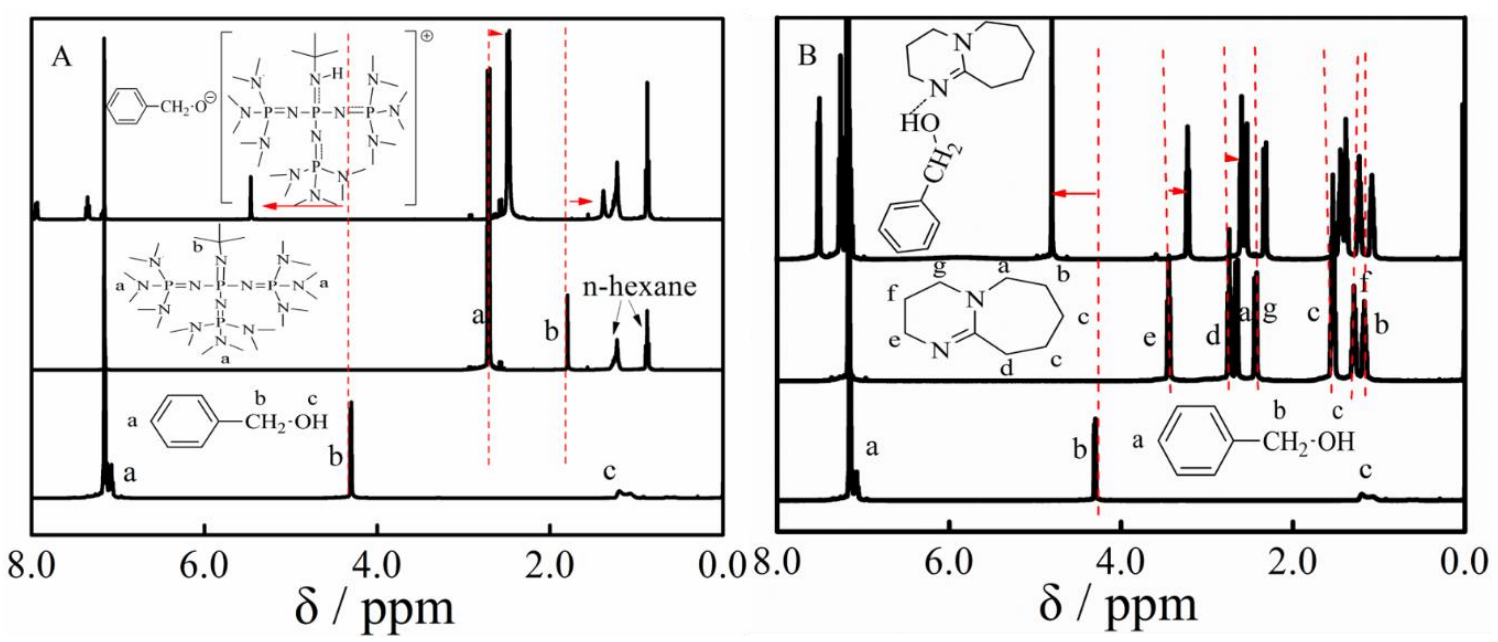

Figure 6. ${ }^{1} \mathrm{H}$ NMR spectra of $(\mathrm{A}) \mathrm{BnOH}, t-\mathrm{BuP}_{4}$ and their $1: 1$ complex in $\mathrm{C}_{6} \mathrm{D}_{6},(\mathbf{B}) \mathrm{BnOH}, \mathrm{DBU}$ and their 1:1 complex in $\mathrm{C}_{6} \mathrm{D}_{6}$. 


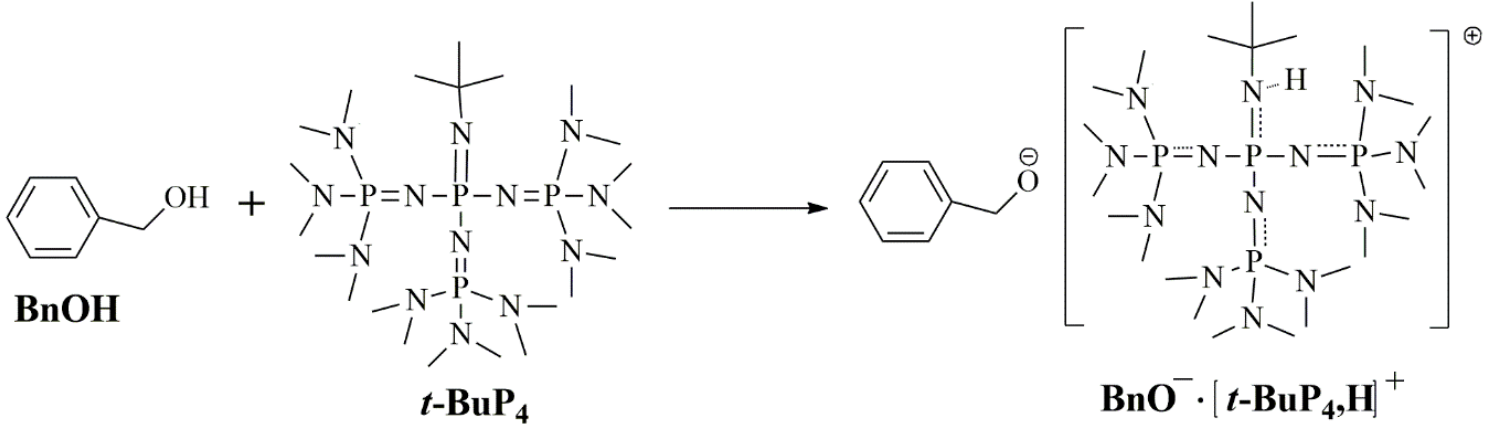

Scheme 3. Generation of $\mathrm{B}_{\mathrm{n}} \mathrm{O}^{-} \cdot\left[t-\mathrm{BuP}_{4}, \mathrm{H}\right]^{+}$as the initiating species for the ROP of DXO.

Figure 7A shows the ${ }^{1} \mathrm{H}$ NMR spectra of $\mathrm{BnOH}, \mathrm{TBD}$ and their $1: 1$ complex in $\mathrm{C}_{6} \mathrm{D}_{6}$, and, in this condition, we conclude the similar results as in $t$ - $\mathrm{BuP}_{4}$ and DBU. TBD and DBU have comparable basicity in MeCN; thus, the large difference in catalytic activity observed for TBD and DBU implies that the thermodynamic basicity is not the sole criterion for the ROP of DXO with these two catalysts. According to the previous publications, the role of TBD in ROP may be bifunctional, and it can also act as a nucleophile [21,37]. Figure 7B shows the ${ }^{1} \mathrm{H}$ NMR spectra of DXO, TBD and their 1:1 complex in $\mathrm{C}_{6} \mathrm{D}_{6}$. There is quite a difference between $\mathrm{DXO}$ and TBD/DXO mixture. TBD could catalyze the ring-opening of $\mathrm{DXO}$, and the formed hydroxyls end should act as the initiator center just as in the catalytic system of DBU and $t$ - $\mathrm{BuP}_{4}$. These results are consistent with that the catalytic activity of TBD is much higher than DBU, and we speculate a possible nucleophilic mechanism for the ROP of DXO with TBD as the catalyst (Scheme 4).
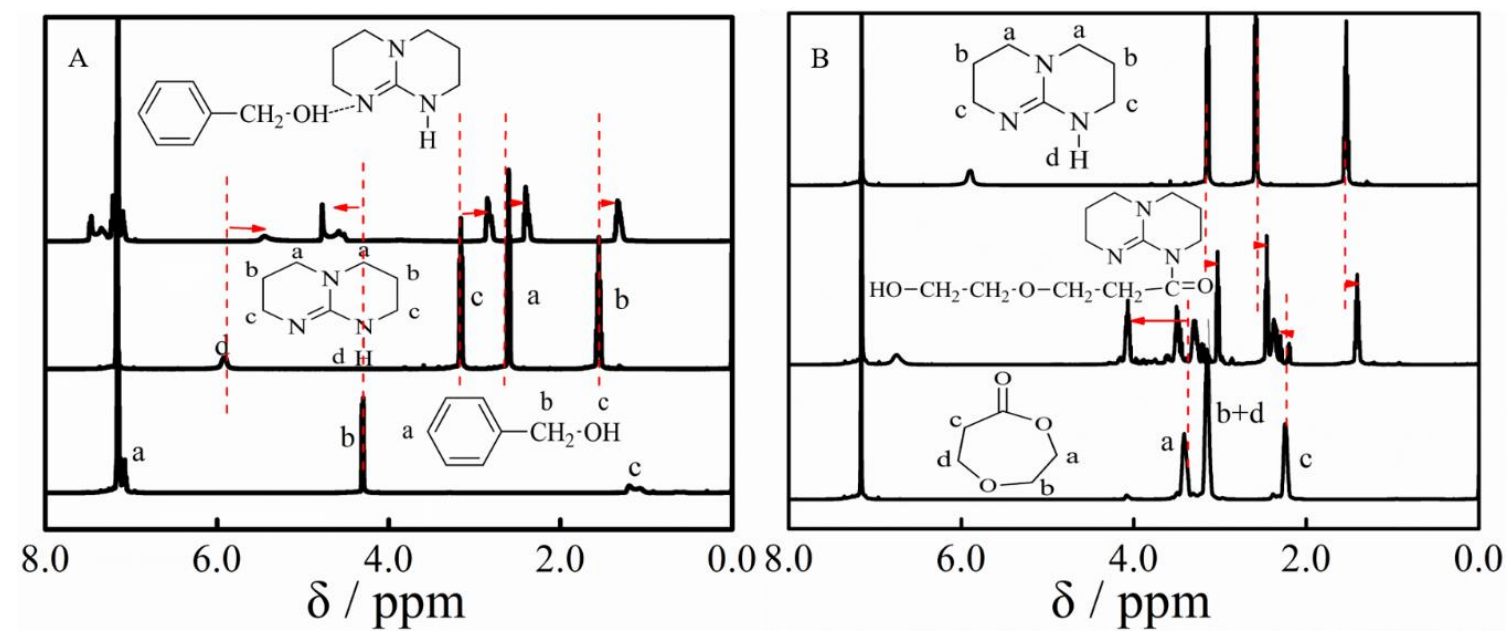

Figure 7. ${ }^{1} \mathrm{H}$ NMR spectra of $(\mathbf{A}) \mathrm{BnOH}, \mathrm{TBD}$ and their $1: 1$ complex in $\mathrm{C}_{6} \mathrm{D}_{6}$; (B) DXO, TBD and their $1: 1$ complex in $\mathrm{C}_{6} \mathrm{D}_{6}$

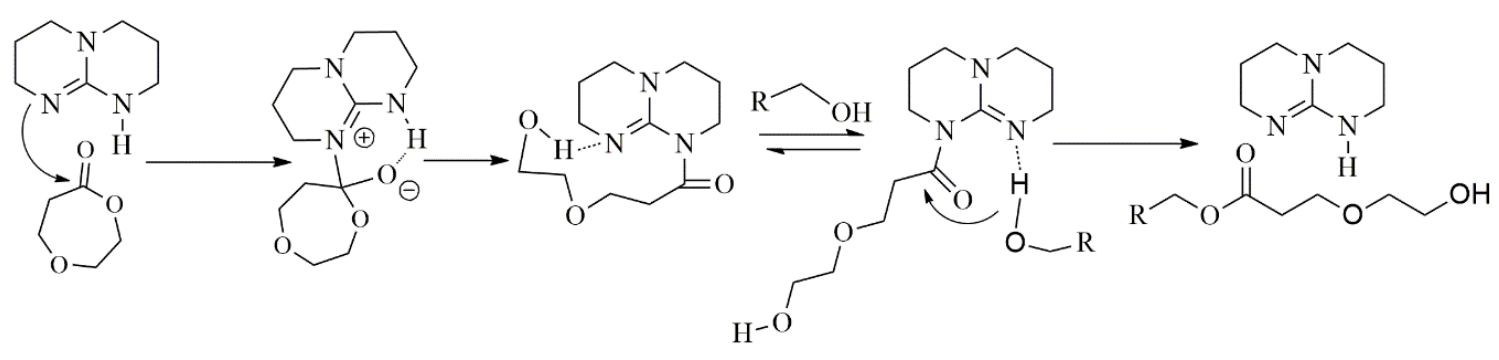

Scheme 4. Proposed nucleophilic mechanism for the ROP of DXO with TBD as the catalyst. 


\section{Conclusions}

1-tert-butyl-4,4,4-tris(dimethylamino)-2,2-bis[tris(dimethylamino) phosphoranylidenamino]$2 \Lambda^{5}, 4 \Lambda^{5}$-catenadi(phosphazene) $\quad(t$-BuP 4$), \quad 1,5,7$-triazabicyclo[4.4.0]dec-5-ene $\quad(\mathrm{TBD})$ and 1,8-diazabicyclo[5.4.0]undec-7-ene (DBU), were used as the 1,5-dioxepan-2-one (DXO) ring-opening polymerization (ROP) catalysts at varied reaction conditions. Both ${ }^{1} \mathrm{H}$ NMR spectra and kinetic studies prove that the polymerization was proceeded in a controlled manner. We have also synthesized the copolymers of DXO with CL and $m$ PEG by the above catalysts. Among them, $t$ - $\mathrm{BuP}_{4}$ shows the highest catalytic behavior and DBU plays the lowest one, which is attributed to the much higher basicity of $t-\mathrm{BuP}_{4}$ than DBU. It is demonstrated that $t-\mathrm{BuP}_{4}$ and DBU proceed the ROP of DXO in an initiator/chain-end mechanism and TBD is in a nucleophilic mechanism, which can also explain the higher catalytic activity of TBD than DBU while with comparable basicity. The organocatalyzed ROP of DXO may provide one useful way for preparing PDXO based biodegradable materials and the application of polyurethane with PDXO as the soft segments are under investigation.

Author Contributions: Writing—original draft preparation and funding acquisition, J.X.; investigation and data curation, Y.C.; formal analysis, W.X.; methodology, J.Z. and M.B.; writing-review and editing, X.Z. and C.L.

Funding: This research was funded by the National Natural Science Foundation of China, grant number 21604015 and 51303193. This research was also funded by Guangdong Key Laboratory Foundation of High Performance and Functional Polymer Materials, grant number 20160003.

Conflicts of Interest: The authors declare no conflict of interest.

\section{References}

1. Jerome, C.; Lecomte, P. Recent Advances in the Synthesis of Aliphatic Polyesters by Ring-Opening Polymerization. Adv. Drug Del. Rev. 2008, 60, 1056-1076. [CrossRef] [PubMed]

2. Hadjichristidis, N.; Iatrou, H.; Pitsikalis, M.; Sakellariou, G. Synthesis of Well-Defined Polypeptide-based Materials via the Ring-Opening Polymerization of $\alpha$-Amino Acid N-Carboxyanhydrides. Chem. Rev. 2009, 109, 5528-5578. [CrossRef]

3. Tian, H.Y.; Tang, Z.H.; Zhuang, X.L.; Chen, X.S.; Jing, X.B. Biodegradable Synthetic Polymers: Preparation, Functionalization and Biomedical Application. Prog. Polym. Sci. 2012, 37, 237-280. [CrossRef]

4. Becker, G.; Wurm, F.R. Functional Biodegradable Polymers via Ring-Opening Polymerization of Monomers without Protective Groups. Chem. Soc. Rev. 2018, 47, 7739-7782. [CrossRef]

5. Irimia-Vladu, M. “Green” Electronics: Biodegradable and Biocompatible Materials and Devices for Sustainable Future. Chem. Soc. Rev. 2014, 43, 588-610. [CrossRef]

6. Mülhaupt, R. Green Polymer Chemistry and Bio-based Plastics: Dreams and Reality. Macromol. Chem. Phys. 2013, 214, 159-174. [CrossRef]

7. Nair, L.S.; Laurencin, C.T. Biodegradable Polymers as Biomaterials. Prog. Polym. Sci. 2007, 32, $762-798$. [CrossRef]

8. Kiesewetter, M.K.; Shin, E.J.; Hedrick, J.L.; Waymouth, R.M. Organocatalysis: Opportunities and Challenges for Polymer Synthesis. Macromolecules 2010, 43, 2093-2107. [CrossRef]

9. Boileau, S.; Illy, N. Activation in Anionic Polymerization: Why Phosphazene Bases are Very Exciting Promoters. Prog. Polym. Sci. 2011, 36, 1132-1151. [CrossRef]

10. Wei, J.; Meng, H.; Guo, B.; Zhong, Z.; Meng, F. Organocatalytic Ring-opening Copolymerization of Trimethylene Carbonate and Dithiolane Trimethylene Carbonate: Impact of Organocatalysts on Copolymerization Kinetics and Copolymer Microstructures. Biomacromolecules 2018, 19, 2294-2301. [CrossRef] [PubMed]

11. Zhao, N.; Ren, C.; Li, H.; Li, Y.; Liu, S.; Li, Z. Selective Ring-Opening Polymerization of Non-strained $\gamma$-Butyrolactone Catalyzed by A Cyclic Trimeric Phosphazene Base. Angew. Chem. Int. Ed. Engl. 2017, 56, 12987-12990. [CrossRef] [PubMed]

12. Xia, Y.N.; Shen, J.Z.; Alamri, H.; Hadjichristidis, N.; Zhao, J.P.; Wang, Y.C.; Zhang, G.Z. Revealing the Cytotoxicity of Residues of Phosphazene Catalysts Used for the Synthesis of Poly(ethylene oxide). Biomacromolecules 2017, 18, 3233-3237. [CrossRef] [PubMed] 
13. Clément, B.; Grignard, B.; Koole, L.; Jérôme, C.; Lecomte, P. Metal-Free Strategies for the Synthesis of Functional and Well-defined Polyphosphoesters. Macromolecules 2012, 45, 4476-4486. [CrossRef]

14. Teng, C.J.; Weber, W.P.; Cai, G. Anionic and Cationic Ring-Opening Polymerization of 2, 2, 4, 4, 6, 6-Hexamethyl-8, 8-divinylcyclotetrasiloxane. Macromolecules 2003, 36, 5126-5130. [CrossRef]

15. Shen, Y.; Zhang, J.; Zhao, N.; Liu, F.; Li, Z. Preparation of Biorenewable Poly( $\gamma$-butyrolactone)- $b$-Poly(l-lactide) Diblock Copolyesters via One-Pot Sequential Metal-Free Ring-Opening Polymerization. Polym. Chem. 2018, 9, 2936-2941. [CrossRef]

16. Ladelta, V.; Kim, J.D.; Bilalis, P.; Gnanou, Y.; Hadjichristidis, N. Block Copolymers of Macrolactones/Small Lactones by a "Catalyst-Switch" Organocatalytic Strategy. Thermal Properties and Phase Behavior. Macromolecules 2018, 51, 2428-2436. [CrossRef]

17. Nederberg, F.; Lohmeijer, B.G.G.; Leibfarth, F.; Pratt, R.C.; Choi, J.; Dove, A.P.; Waymouth, R.M.; Hedrick, J.L. Organocatalytic Ring Opening Polymerization of Trimethylene Carbonate. Biomacromolecules 2006, 8, 153-160. [CrossRef]

18. Yuen, A.Y.; Lopez-Martinez, E.; Gomez-Bengoa, E.; Cortajarena, A.L.; Aguirresarobe, R.H.; Bossion, A.; Mecerreyes, D.; Hedrick, J.L.; Yang, Y.Y.; Sardon, H. Preparation of Biodegradable Cationic Polycarbonates and Hydrogels through the Direct Polymerization of Quaternized Cyclic Carbonates. ACS Biomater. Sci. Eng. 2017, 3, 1567-1575. [CrossRef]

19. Feng, J.; Zhuo, R.X.; Zhang, X.Z. Construction of Functional Aliphatic Polycarbonates for Biomedical Applications. Prog. Polym. Sci. 2012, 37, 211-236. [CrossRef]

20. Lohmeijer, B.G.G.; Pratt, R.C.; Leibfarth, F.; Logan, J.W.; Long, D.A.; Dove, A.P.; Nederberg, F.; Choi, J.; Wade, C.; Waymouth, R.M. Guanidine and Amidine Organocatalysts for Ring-Opening Polymerization of Cyclic Esters. Macromolecules 2006, 39, 8574-8583. [CrossRef]

21. Pratt, R.C.; Lohmeijer, B.G.G.; Long, D.A.; Waymouth, R.M.; Hedrick, J.L. Triazabicyclodecene: A Simple Bifunctional Organocatalyst for Acyl Transfer and Ring-Opening Polymerization of Cyclic Esters. J. Am. Chem. Soc. 2006, 128, 4556-4557. [CrossRef] [PubMed]

22. Brown, H.A.; de Crisci, A.G.; Hedrick, J.L.; Waymouth, R.M. Amidine-Mediated Zwitterionic Polymerization of Lactide. ACS Macro Lett. 2012, 1, 1113-1115. [CrossRef]

23. Yang, H.; Xu, J.; Pispas, S.; Zhang, G. Hybrid Copolymerization of $\varepsilon$-Caprolactone and Methyl Methacrylate. Macromolecules 2012, 45, 3312-3317. [CrossRef]

24. Zhao, J.; Schlaad, H.; Weidner, S.; Antonietti, M. Synthesis of Terpene-Poly(ethylene oxide)s by t-BuP 4 -Promoted Anionic Ring-Opening Polymerization. Polym. Chem. 2012, 3, 1763-1768. [CrossRef]

25. Xia, Y.N.; Chen, Y.; Song, Q.L.; Hu, S.Y.; Zhao, J.P.; Zhang, G.Z. Base-to-Base Organocatalytic Approach for One-Pot Construction of Poly(ethylene oxide)-based Macromolecular Structures. Macromolecules 2016, 49, 6817-6825. [CrossRef]

26. Li, H.; Luo, H.; Zhao, J.; Zhang, G. One-Step Approach to Polyester-Polyether Block Copolymers Using Highly Tunable Bicomponent Catalyst. ACS Macro Lett. 2018, 7, 1420-1425. [CrossRef]

27. Loefgren, A.; Albertsson, A.C.; Dubois, P.; Jerome, R.; Teyssie, P. Synthesis and Characterization of Biodegradable Homopolymers and Block Copolymers based on 1, 5-Dioxepan-2-one. Macromolecules 1994, 27, 5556-5562. [CrossRef]

28. Andronova, N.; Srivastava, R.K.; Albertsson, A.C. Potential Tissue Implants from the Networks based on 1, 5-Dioxepan-2-one and $\varepsilon$-Caprolactone. Polymer 2005, 46, 6746-6755. [CrossRef]

29. Van der Meulen, I.; Li, Y.; Deumens, R.; Joosten, E.A.; Koning, C.E.; Heise, A. Copolymers from Unsaturated Macrolactones: Toward the Design of Cross-linked Biodegradable Polyesters. Biomacromolecules 2011, 12, 837-843. [CrossRef]

30. Stjerndahl, A.; Wistrand, A.F.; Albertsson, A.C. Industrial Utilization of Tin-initiated Resorbable Polymers: Synthesis on A Large Scale with A Low Amount of Initiator Residue. Biomacromolecules 2007, 8, 937-940. [CrossRef]

31. Odelius, K.; Plikk, P.; Albertsson, A.C. Elastomeric Hydrolyzable Porous Scaffolds: Copolymers of Aliphatic Polyesters and A Polyether-ester. Biomacromolecules 2005, 6, 2718-2725. [CrossRef] [PubMed]

32. Mathisen, T.; Albertsson, A.C. Polymerization of 1,5-Dioxepan-2-one. I. Synthesis and Characterization of the Monomer 1,5-Dioxepan-2-one and Its Cyclic Dimer 1,5,8,12-Tetraoxacyclotetradecane-2,9-dione. Macromolecules 1989, 22, 3838-3842. [CrossRef] 
33. Mathisen, T.; Masus, K.; Albertsson, A.C. Polymerization of 1,5-Dioxepan-2-one. II. Polymerization of 1,5-Dioxepan-2-one and Its Cyclic Dimer, Including a New Procedure for the Synthesis of 1,5-Dioxepan-2-one. Macromolecules 1989, 22, 3842-3846. [CrossRef]

34. Löfgren, A.; Albertsson, A.C. Synthesis and Characterization of High Molecular Weight Poly(1,5-dioxepan-2-one) with Narrow Molecular Weight Distribution. Polymer 1995, 36, 3753-3759. [CrossRef]

35. Macdonald, J.P.; Sidera, M.; Fletcher, S.P.; Shaver, M.P. Living and Immortal Polymerization of Seven and Six Membered Lactones to High Molecular Weights with Aluminum Salen and Salan Catalysts. Eur. Polym. J. 2016, 74, 287-295. [CrossRef]

36. Höglund, A.; Albertsson, A.C. Spontaneous Crosslinking of Poly(1,5-dioxepan-2-one) Originating from Ether Bond Fragmentation. J. Polym. Sci. Part. A Polym. Chem. 2008, 46, 7258-7267. [CrossRef]

37. Kiesewetter, M.K.; Scholten, M.D.; Kirn, N.; Weber, R.L.; Hedrick, J.L.; Waymouth, R.M. Cyclic Guanidine Organic Catalysts: What is Magic about Triazabicyclodecene. J. Org. Chem. 2009, 74, 9490-9496. [CrossRef] [PubMed]

(C) 2019 by the authors. Licensee MDPI, Basel, Switzerland. This article is an open access article distributed under the terms and conditions of the Creative Commons Attribution (CC BY) license (http://creativecommons.org/licenses/by/4.0/). 